this energy transformation is negligible, but the effect on the colour-rendering properties of the emitted light is appreciable and useful. The second type of fluorescent light source is exemplified in the 80 watt MCF/U lamp, which was put on the market in March 1940, and is being used extensively for industrial lighting. A fluorescent powder layer coated on the inside surface of the tube containing a low-pressure mercury discharge tube is so vigorously excited by the resonance radiation from mercury that it produces about ten times the light given by an uncoated tube of similar size. The light is white and has colour-rendering properties sufficiently close to those of daylight for most industrial applications. The fluorescent layer is a mixture of inorganic powders which if used separately would give blue, yellow and red light and they are most efficiently activated by radiation of wave-length $2,537 \mathrm{~A}$.

As the 80-watt lamp was designed primarily for industrial lighting to meet the demands of war-time conditions, the major applications in Great Britain have been in industry. Much experience has, however, been gained in the United States, where in the last three years fluorescent lamps have been introduced into practically every lighting field. It is found that the low surface brightness of approximately 0.5 candle per sq. cm. in the case of the 80-watt lamp and the large size of the source render it of great value for producing illumination conditions which can be made to approach daylight interior lighting. Shadows are softened and in a well-designed installation the illumination of vertical planes can be made effectively. In most cases stroboscopic effects are of little importance, the phosphorescence of certain of the powders used in the lamp construction assisting in bridging the gap between the cyclic changes in light output. The psychological effect of apparently cool light has proved advantageous in certain industries, and the freedom from glare in a well-designed installation is a noteworthy feature.

\section{A Projected Canal System for England}

IN a booklet entitled "The Projected Grand Contour Canal" (Birmingham : Cotterell and Co., 2s.), Mr. J. F. Pownall describes his ideas of a waterway linking together the main ports of England and accessible to coasting vessels up to 1,500 tons displacement, as well as canal barges. He points out that in the main watersheds of England, the lowest cols are at approximately $300 \mathrm{ft}$. As a result, he plans this canal to follow as near as possible the $310 \mathrm{ft}$. contour, which would obviate canal locks, with their delay and cost of upkeep, and necessitate only a few tunnels. Already some two hundred miles of existing canals lie at about $300 \mathrm{ft}$.; others are at lower levels. These might be linked by lifts, which have the advantage over locks in that they do not lose water in operation.

The main canal and its chief branches would be 864 miles long and would be $100 \mathrm{ft}$. wide at the water level, $17 \mathrm{ft}$. deep, with a clear headway under bridges of $80 \mathrm{ft}$. From London the Lea navigation would be used and improved as far as Hertford, where the new canal would begin with a lift. Thence it would pass through. Bletchley, Rugby, Lichfield and Market Drayton to Manchester, with branches to Birmingham, the Trent and Wrexham. Through Lancashire it would pass by Clitheroe and Skipton, with a branch to Bradford and the Aire and Calder navigation, and thence along the eastern flank of the Pennines to Richmond and Newcastle, with a branch to Hartlepool. In the south, branches would reach Bristol and Southampton. At or near all the great ports, lifts would operate to and from the $310 \mathrm{ft}$. level. Sixty per cent of industrial England would thus be served at a cost which Mr. Pownall estimates at a halfpenny per ton mile. Other features of the suggested canal would be its service as a "water grid' and as a line for gas, oil and other pipes which could be laid on its bed.

\section{Wood Pigeon Nest Census}

As ecological survey of the wood pigeon's breeding habitats in Great Britain is being organized by the Edward Grey Institute, Museum Road, Oxford, as part of the British Trust for Ornithology's investigation into the biology of this species. The basis of the survey is a punch card, one being used for each occupied nest. The card is printed with a simple system of habitat classification; types of wood are illustrated by stating the name of the chief tree, shrub and flower. The finder also gives details of the position and contents of the nest, completing the hatching and fledging records if there are opportunities of returning to the nest. A punch card may be used at any time when a nest is found, but the maximum information is obtained from a census of any area of known acreage. If possible the census is repeated each month, cards being made out for nests not previously discovered and fresh information added to the old ones. The scheme is therefore flexible, allowing contributions from either an individual with only a few minutes to spare, or from members of a team; it also allows scope for organization within the team, encouraging those with specialized knowledge, such as a botanist, photographer, 'surveyor', and so on. For those proposing to organize a team census a pamphlet "How to Organise a Wood Pigeon Nest Census" is available from the Institute.

As the most active members of the Trust are now serving with the Forces a special appeal is being made to schools and youth organizations to help with the census. Several biology teachers are now using pigeons in dissection classes, and are studying crop contents, checking their identifications with observations in the field. A leaflet "Directions for Biologists" is available for anyone willing to undertake the examination of pigeons.

\section{Lodgewood Telegraph Poles}

C. H. Amadon, in an article on this subject (Bell Lab. Rec., 20, No. 6, Feb., 1942), refers first to initial experiments made to preserve pine poles by creosoting, and secondly describes the method finally adopted. In the latter the poles are placed in closed cylinders and compressed air is admitted for about half an hour until the pressure rises to about $85 \mathrm{lb}$. per sq. in. Some of this air enters the cells of the wood. Hot creosote is then pumped in until the cylinder is full, pressure being maintained at $85 \mathrm{lb}$. per sq. in. during this period. More hot creosote is next pumped in until the pressure rises to about $135 \mathrm{lb}$. per sq. in. During this period of nearly three hours the creosote is taken up by the wood and fills its cells. At the end of this pumping period, air pressure is released and a vacuum is created under which the entrapped air brings to the surface most of the excess creosote, which drips off and is pumped out of the cylinder. The vacuum is broken after about an hour and live steam at a pressure of $20 \mathrm{lb}$. per sq. in. and a temperature of $260^{\circ} \mathrm{F}$. is admitted 
to the cylinders and maintained for three hours to re-establish pressure in the wood and increase the fluidity of the remaining creosote. A vacuum is then drawn again and held for an hour, during which time more of the creosote comes to the surface and drips off. The vacuum is then broken and the cylinders are opened. Any liquid creosote on the surface of the poles is quickly reabsorbed, and the poles are reasonably clean. The first charge treated in this way completely satisfied all requirements. Approximately 50,000 full-length pressure-creosoted lodgepole pine poles have been treated according to the process described, with a high degree of conformity to the desired results in terms of penetration, consumption of creosote and cleanliness of the poles.

\section{X-Ray Reflexion and Scattering with Frequency Change}

THEORY and experimental work on the quantum reflexion and quantum scattering of $\mathrm{X}$-rays are dealt with by Sir C. V. Raman in two papers (Proc. Roy. Soc., A, 179, $289 ; 1942$ ). The quantum or modified scattering is due to the excitation of the elastic solid or low-frequency vibrations of the crystal lattice by the $\mathbf{X}$-ray photon. It has a very low specific intensity proportional to $N$ (the number of lattice cells) and is distributed over a wide range of solid angles. The quantum or modified reflexion is due to the excitation of the infra-red or characteristic high-frequency vibrations of the crystal lattice by the $\mathrm{X}$-ray photons. Its intensity, like that of the classical or unmodified reflexions, is of the order $N^{2}$, though usually smaller in absolute value than the intensity of the classical reflexions. The frequency changes which play a fundamental part in the theory of both phenomena appear as necessary consequences of both the classical and quantum theoretical points of view, but the law of intensity variation with temperature is quite different in the classical and quantum formulations. Experimental studies at low temperatures are specially important for the differences between the two theories. The influence of the modified X-ray reflexions on the intensity of the classical reflexions and their variation with temperature are discussed and shown to be of even greater importance then the effect on the same of the X-ray scattering by the elastic solid vibrations. In the second paper experimental results on diamond are reported agreeing with the theory.

\section{An Improved Capacitance Bridge for Precision Measurements}

To meet the demand for increased precision a new standardizing capacitance bridge, known as the No. 12 type, has recently been developed by the Bell Telephone Laboratories and is now described by W. D. Voelker (Bell Lab. Rec., 20, No. 5; 1942). This bridge, operating at frequencies up to $200 \mathrm{kc}$., has a range of from 0 to $l \cdot 11 \mu F$., and from 0 to 1000 umhos. It is of the equal-ratio-arm type, the arms being of woven-wire resistance. A slide wire at the junction of the two resistances and an air condenser that allows capacitance to be shifted from one arm to the other, permit a small amount of adjustment that may be required at infrequent intervals to offset the effects of ageing. The resistances form the adjacent ratio arms of the bridge, and permit an unknown capacitance in a third arm to be measured against an adjustable standard capaci- tance in the fourth. This is the basic principle of the bridge. Conductance standards are included in the bridge. For measuring the larger values of capacitance silvered-mica condensers are employed as standards, while for smaller values of capacitance, air condensers are more convenient. The air-condenser standard consists of three decades of fixed capacitance and a movable plate condenser for fine adjustment. The control dial is calibrated to indicate directly the capacitance of the unknown for each position of the dial.

\section{Medical Services in Sweden}

THe March issue of the Anglo-Swedish Review gives an interesting account by Torsten Trietz of the organization of medical services in Sweden. Preventive medicine is administered by public health officers, of whom there is one in each of the twentyfour counties and larger eities. Outdoor medical treatment is provided by the following groups of physicians : (1) in the provinces the district doctor is a State official appointed for the medical care of the population in rural districts, who receives a fixed salary and retiring allowance; (2) urban physicians, who are also salaried physicians but are paid by the municipality; (3) private practitioners who are also paid a salary. Owing to their social importance tuberculosis and venereal diseases are compulsorily notifiable and free treatment is provided. There is a panel service national health insurance, of which the cost is borne partly by the State and partly by the fees of the insured. The public indoor service is mainly provided in general hospitals and is administered by the county councils or municipal councils, and paid for by the taxpayers. The hospital treatment of tuberculosis is organized in sanatoria, of which there are about 100 with about 8,000 beds. Care of infectious diseases in fever hospitals is compulsory for certain diseases and is free. Radiological treatment of malignant growths and similar diseases is organized in special eancer clinies at Stockholm, Gothenburg, Lund and Uppsala. All indoor relief of mental cases is administered by the State in some twenty hospitals containing 17,000 beds. The nurses in Sweden receive three years training in the larger hospitals in co-operation with the Swedish Red Cross. Midwives are trained at two colleges, and treat the vast majority of cases of ehildbirth.

\section{Courses of the Lower Ganges}

THE November issue of Science and Culture, which is conducted by the Indian Science News Association with the aim of advocating the application of scientific knowledge to the national welfare of India, contains an interesting article on the antiquity of the Lower Ganges and its courses. Mr. N. K. Bhattasali approaches the subject from the historical point of view. Little that is very definite emerges from Mahabharata and Pauranic literature, though a certain amount of evidence as regards the various mouths of the river suggests relatively few major changes. Ptolemy in A.D. 150 gave a full account of the Lower Ganges, and Mr. Bhattasali finds that, allowing the necessary corrections for Ptolemy's longitudes, the five mouths of the river are in approximately the same longitudes to-day as about nineteen hundred years ago. There are several maps in the article, including Rennell's map of 1761 and van den Broucke's of 1660 . 